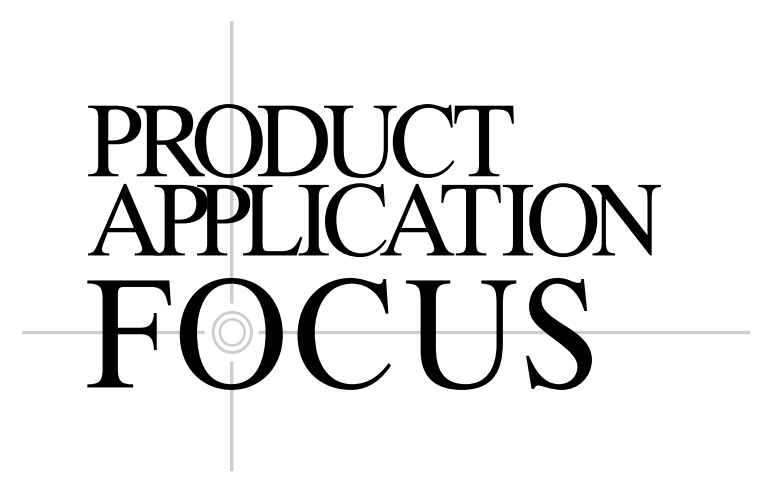

... a forum for manufacturers to describe the current and potential applications of new research instruments or products.

\title{
Fully Automated Radioligand Binding Filtration Assay for Membrane-Bound Receptors
}

\author{
A. Shrikhande, C. Courtney, D. Smith, M. Melch, M. McConkey, \\ J. Bergeron, and Stephen K-F. Wong \\ Pfizer Global Research and Development, Pfizer, Groton, CT, USA
}

BioTechniques 33:932-937 (October 2002)

\begin{abstract}
Here we describe a fully automated, hands-free radioligand filtration binding assay for dopamine D3 receptors. Three separate instruments were linked in tandem to perform the following operations: The Genmate and Genesis were linked to perform liquid handling, incubation, and the scheduling operations, while an automated harvester was used to perform rapid filtration. To minimize carryover of compounds, disposable tips were used for diluting and dispensing the compounds. A custom-designed tip holder was used to handle loading and pipetting by the Genmate 96-well pipettor. The assay for 84 compounds with six concentrations that spans six logs can be completed within $4 \mathrm{~h}$. The reproducibility of the individual data point ( $\mathrm{CV}<10 \%$ between duplicates) and $K_{i}(\mathrm{CV}<20 \%)$ is superior to that determined by manual procedures. $K_{i}$ values of various dopamine ligands determined by the hands-free procedure are similar to published values. This technology reduces hands-on time (at least 70\%), minimizes exposure to radioligands (up to 95\%), and improves the reproducibility of results. The technology is applicable for high-throughput screening and rapid determination of structure-activity relationship of compounds for many other membrane-bound receptors.
\end{abstract}

\section{INTRODUCTION}

Radioligand binding assay using rapid filtration is the most widely used assay to characterize the potency and selectivity of compounds for many receptors of neurotransmitters and hormones. The assay involves incubating membrane preparations with radioligand in the presence of varying concentrations of compounds. Upon completion of incubation, radioligand bound to the membrane-bound receptors is separated from the free radioligand by rapid filtration through glass fiber filters. The amount of radioligand bound to the target receptor is determined by scintillation counting. The procedure requires liquid handling, incubation, and filtration, which are typically performed manually. The operations require constant hands-on operations, and this makes it difficult to minimize the exposure to radioactivity that is the main hazard of the assay.

Reproducibility between data points within a single experiment and between experiments is the key to establish the potency of any compound in any filtration binding assay. This is affected by several factors, including multiple pipetting steps and the degree of experience of the operator. Although the variability of the assay has been minimized by the use of automated liquid pipetting workstations, filter plates, semi-automatic harvesters, and multichannel pipets, the variability of the data can be up to 3-fold between experiments. Standardization of the assay by robotic liquid handling can increase the reproducibility and throughput. Semi-automatic radioligand binding assays have been published previously $(2,5)$, and hands-free operation of the assay has not been reported. Here we describe a fully hands-free automated workstation to perform the filtration binding assay in a normal laboratory 
setting. Compared to manual operations, the automated assay has improved reproducibility and requires much less handson time. The time of exposure to radioactivity can be reduced by more than 10 - to 20 -fold. This automated operation is readily applicable to any filtration radioligand binding assay and can be adapted to a variety of other similar assays.

\section{MATERIALS AND METHODS}

The Genmate automated 96-well pipettor and the Genesis 200 liquid handling system with incubators and robotic arms were both from Tecan (Durham, NC, USA). The automated harvester was from Brandel (Gaitersburg, PA, USA). The robotic workstations were arranged as shown in Figure 1. A pair of extended robotic fingers at the Genesis was made to transfer microplates, filter plates, and pipet tips among the three machines. The software to control the operations for Genmate was GenEditor version 1.23, while Gemini 3.2 runs Genesis. The software to control the Brandel automated harvester was from the manufacturer. Software to control scheduling operations (Facts 4.8) was from Tecan.

Cooling trough, reagent troughs, holders for microplates and deep-well plates, incubator, and hotel for microplates were from Tecan. The Spacesaver ${ }^{\mathrm{TM}}$ Tip Racks containing the pipet tips (20-200 $\mu \mathrm{L})$ were from Rainin. Each rack contains nine cartridges of 96 pipet tips, and as many as four racks can be stored at the Genesis deck, as shown in Figure 1. Each cartridge of tips can be transferred from the rack to the holder for the Rainin pipet tip cartridge at Genmate by the robotic fin- gers in Genesis. This custom-designed holder has an air pressure-driven clamp that holds the cartridge of pipet tips during the pipetting operations. The opening and closing of the clamp are controlled by Gemini 3.2.

TOPCOUNT.NXT and Unifilter plates with GF/B filters were from Packard Instruments (Meriden, CT, USA). [ $\left.{ }^{3} \mathrm{H}\right]-7-$ OH-DPAT was from NEN ${ }^{\circledR}$ Life Science Products (Boston, MA, USA). L-741 626, haloperidol, and other D3 ligands were from Sigma-RBI (Natick, MA, USA). All other reagents were from Sigma (St. Louis, MO, USA).

\section{Preparation of Membrane}

Chinese hamster ovary cells that stably express human dopamine D3 receptors were licensed from Sokoloff et al. (11). The D3 receptor-expressing cells were homogenized two times using a Polytron (20 s, setting 6) in assay buffer containing $50 \mathrm{mM}$ Tris, $\mathrm{pH}$ 7.4, $120 \mathrm{mM} \mathrm{NaCl}, 5 \mathrm{mM} \mathrm{KCl}, 2$ $\mathrm{mM} \mathrm{CaCl} 2,5 \mathrm{mM} \mathrm{MgCl}_{2}$. The homogenate was centrifuged after each homogenization at $20000 \mathrm{rpm}$ at $4^{\circ} \mathrm{C}$ for $10 \mathrm{~min}$. The pellet was resuspended in assay buffer at a concentration of $10 \mathrm{mg}$ protein $/ \mathrm{mL}$ and stored in frozen aliquots at $-80^{\circ} \mathrm{C}$. Protein content was determined by BCA assay (Pierce Chemical, Rockford, IL, USA) using BSA as standard.

\section{Instrument Setup}

Figure 1 shows the layout of the setup of two Tecan liquid handlers (Genmate and Genesis) and a Brandel automated

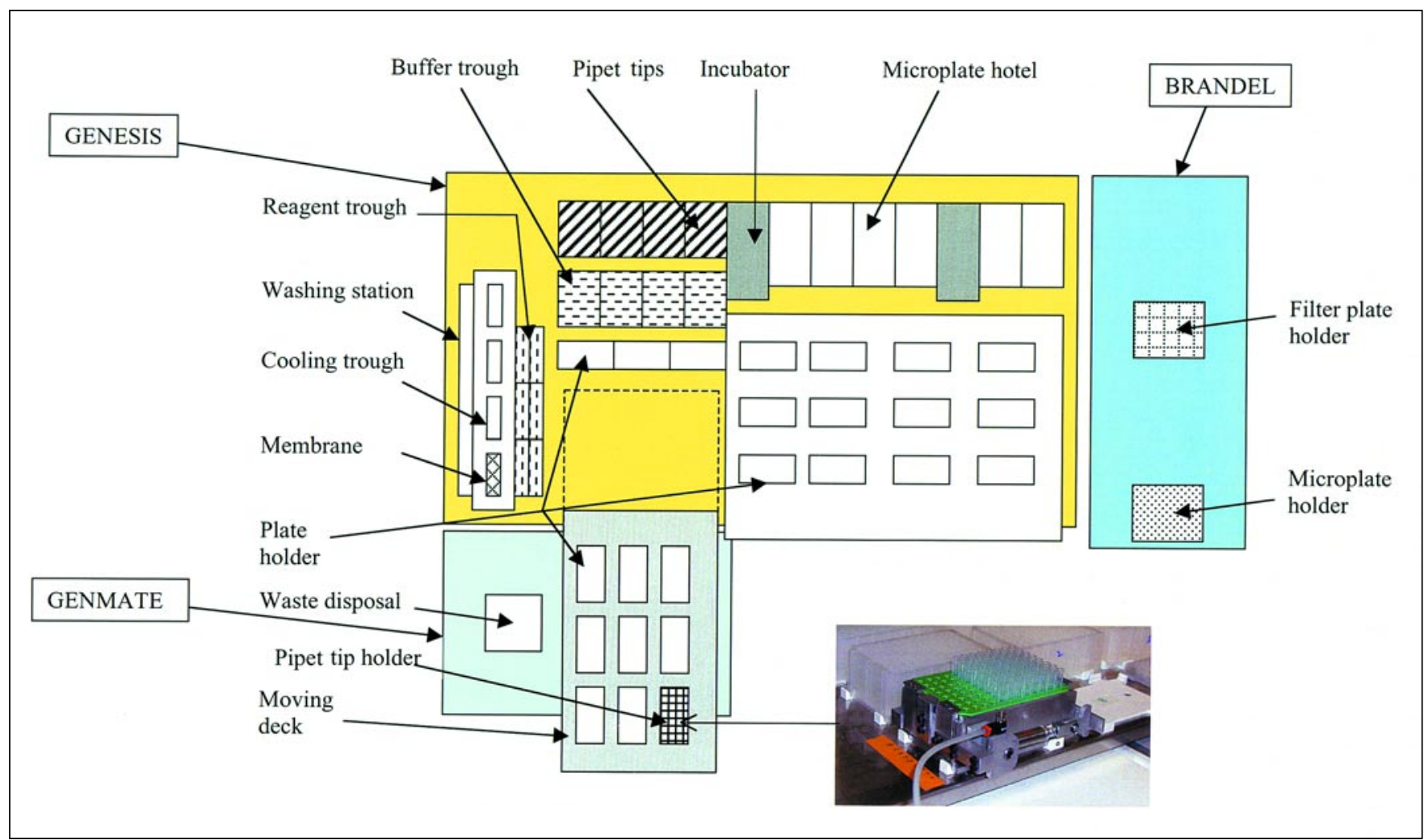

Figure 1. Layout of the instrumentation to enable a fully automated receptor binding assay. The Genmate and Genesis liquid handlers and a Brandel automated harvester were linked as shown. The various workstations and racks are indicated in the figure. Genesis and Genmate performed the liquid-handling operations. Incubation of the binding reactions was performed at the Genesis deck, after which the reactions were terminated by rapid filtration at the Brandel automated harvester, as described in the Materials and Methods section. The inset shows the picture of the custom-made holder for the disposable pipet tip cartridges. 
harvester to enable a fully automated receptor binding assay. Genesis and Genmate performed all liquid-handling operations. Incubation of the binding reactions was performed at the Genesis deck, after which the reactions were terminated by rapid filtration at the Brandel automated harvester.

\section{Liquid Handling}

Before the dilution of compounds, $120 \mu \mathrm{L} /$ well of $0.5 \%$ polyethyleneimine was added to the Unifilter GF/B plates using the fixed tips of Genesis. Each tip was washed with $5 \mathrm{~mL}$ water, followed by $1 \mathrm{~mL}$ DMSO, and then $30 \mathrm{~mL}$ water. Vehicle (10\% DMSO) was then added to each well of six 2-mL deep well plates (Waters, Franklin, MA, USA) for subsequent dilutions of compounds. The deep well plates were then transferred by the ROMA fingers to the Genmate deck for dilutions. Test compounds ( $1 \mathrm{mM}$ stock concentration, 200-300 $\mu \mathrm{L})$ were dissolved in $100 \%$ DMSO and stored in $0.75 \mathrm{~mL}$ deep well plates (Matrix Technologies, Hudson, NH, USA). Disposable tips were used for all subsequent dilutions and transfer operations, using the custom-designed pipet tip holder as shown in Figure 1. Compounds were serially diluted by 10 -fold dilution in $10 \%$ DMSO from $1 \mathrm{mM}$ to $0.1 \mathrm{nM}$. The diluted compounds were transferred $(25 \mu \mathrm{L} /$ well in duplicates) to microplates (Corning, Corning, NY, USA). Butaclamol $(25 \mu \mathrm{L} 100 \mu \mathrm{M})$ (final concentration, $10 \mu \mathrm{M}$ in $10 \%$ DMSO) and $25 \mu \mathrm{L} 10 \%$ DMSO (six replicates) was also pipetted to each microplate by Genmate. These wells will be used for determination of nonspecific and total counts. The microplates were then transported back to the hotel.

\section{Incubation and Harvesting}

Twenty-five microliters of $\left[{ }^{3} \mathrm{H}\right]-7-\mathrm{OH}-\mathrm{DPAT}(0.4-0.6 \mathrm{nM}$ final concentration) were added to each well followed by 150 $\mu \mathrm{L}$ assay buffer. The reaction was initiated by the addition of $50 \mu \mathrm{L}$ membrane preparation (3-5 $\mu \mathrm{g} /$ well), which was kept at $2^{\circ} \mathrm{C}$ at the cooling trough. Incubation was for $15 \mathrm{~min}$ at $37^{\circ} \mathrm{C}$ in the incubator, after which the reaction was terminated by rapid filtration through the polyethyleneimine soaked Unifilter GF/B filter plates prepared earlier. The plates were washed six times $(200 \mu \mathrm{L} /$ wash/well $)$ with ice-cold $50 \mathrm{mM}$ Tris buffer, $\mathrm{pH} 7.4$, in the Brandel harvester. Filter plates were transferred back to the hotel and air-dried overnight at room temperature. Afterwards, $40 \mu \mathrm{L}$ MicroScin 0 (Packard Instrument) was pipetted into each well of the Unifilter plate and counted in the TOPCOUNT.NXT counter.

\section{Scheduling}

Figure 2 shows the scheduling of the robotic operations. Dilution of 84 compounds and the subsequent transfer to 12 microplates were performed first. The addition of radioactivity and membrane preparations, incubation, and filtration operations were all scheduled and staggered such that there was identical time of incubation ( $15 \mathrm{~min}$ ) for each microplate. The total time of the automated operation is $3 \mathrm{~h} 50 \mathrm{~min}$ for 84 compounds.

\section{Manual Radioligand Binding Assay}

The manual radioligand binding assay was performed in a similar fashion to the automated assay described above, except that the reaction was terminated by rapid filtration through Brandel Whatman GF/B FILTERMATE filters (previously soaked in $0.5 \%$ polyethyleneimine for $2 \mathrm{~h}$ and dried) with ice-cold $50 \mathrm{mM}$ Tris buffer, $\mathrm{pH} 7.4$, in the Skatron harvester (Molecular Devices, Sunnyvale, CA, USA). Filters

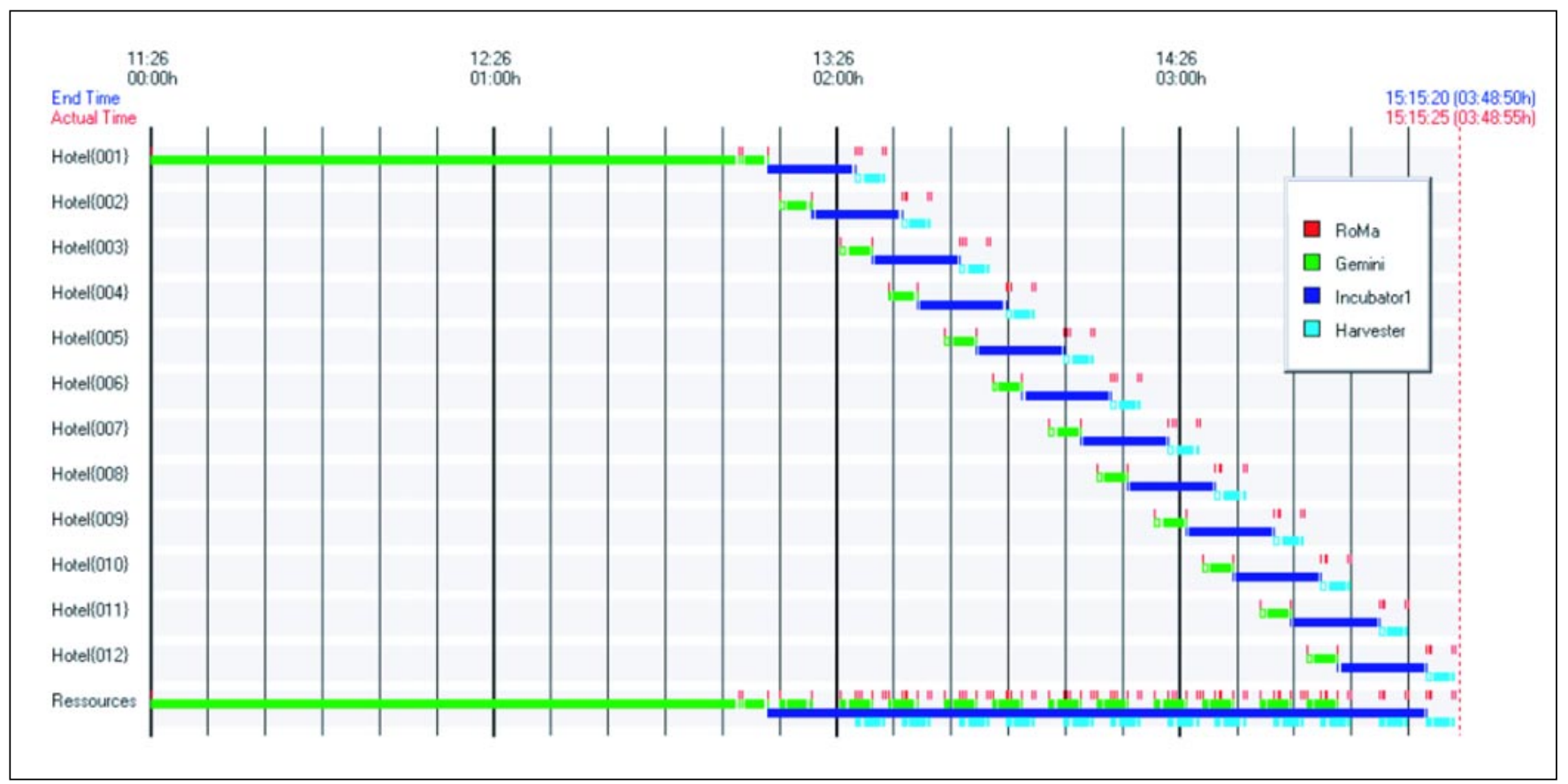

Figure 2. Scheduling of the robotic operations. Dilution of 84 compounds and the subsequent transfer to 12 microplates were performed first as shown in the long green bar on the left. The addition of radioactivity and membrane preparations and incubation and filtration operations were all scheduled such that there is identical time of incubation $(15 \mathrm{~min})$ for each microplate. The later staggered operations were shown with the green-dark blue-light blue bars as shown. The red bars denote the operations of the robotic fingers. 
were air-dried overnight and counted in the Beta counter using Betaplate Scint (both from Wallac, Turku, Finland).

\section{Scatchard Analysis}

Scatchard analysis was performed manually as described in the automated procedure. Membranes were incubated with indicated concentrations of $\left[{ }^{3} \mathrm{H}\right]-7-\mathrm{OH}-\mathrm{DPAT}$ in a final volume of $250 \mu \mathrm{L}$ for $15 \mathrm{~min}$ and were harvested either by the Skatron or Brandel harvester as described above.

\section{Data Analysis}

Scintillation counts from the TopCount were recorded in a computer and were transferred online to another computer with the data analysis software. $\mathrm{K}_{\mathrm{i}}$ was determined by nonlinear regressions as described by Marquardt (7) using the Data Analysis Toolbox software package (Molecular Designs Limited, San Leandro, CA, USA). Analysis of the data and plotting of the graphs for 84 compounds can be completed within $5 \mathrm{~min}$.

For Scatchard analysis, $B_{\max }$ and $\mathrm{K}_{\mathrm{d}}$ from the saturation binding assay was determined by the curve fitting program from GraphPad Prism ${ }^{\mathrm{TM}}$.

\section{RESULTS}

\section{$K_{d}$ Determination Using the Brandel Harvester}

Rapid filtration to separate free and bound radioligands in the automated assay was performed using the Brandel automated harvester with the Unifilter plate. To validate the instrument and filter plates for the assay, the saturation binding assay was performed manually using either the Skatron or the Brandel harvester. A single class of binding sites of $\left[{ }^{3} \mathrm{H}\right]-7-$ OH-DPAT with $\mathrm{K}_{\mathrm{d}}$ of $1.3 \mathrm{nM}$ was obtained in both harvesters (Figure 3). $\mathrm{K}_{\mathrm{d}}$ values were similar to that of the published reports of $\left[{ }^{3} \mathrm{H}\right]-7-\mathrm{OH}-\mathrm{DPAT}$ for D3 $(3,4,6)$. These results suggest that the Brandel automated harvester can be used for rapid filtration assays to determine $\mathrm{K}_{\mathrm{i}}$ of compounds. $\mathrm{B}_{\max }$ determined by the Brandel harvester was $30 \%$ less than that from the Skatron harvester. This is a result of the difference in recovery of the membranes between the two harvesters during rapid filtration, as $30 \%-50 \%$ more membrane preparation is routinely required in the Brandel harvester to achieve a bound count similar to the Skatron harvester (results not shown).

\section{Reproducibility}

To determine the validity and reproducibility of the automatic operation, haloperidol $\left(\mathrm{K}_{\mathrm{i}}=2.9 \mathrm{nM}\right)(10)$ and $\mathrm{L}-$ $741626\left(\mathrm{~K}_{\mathrm{i}}=120 \mathrm{nM}\right)(1)$, which have different affinity for the dopamine D3 receptors, were used to validate the automated assay. These compounds were tested several times in 12 plates. Figure 4 shows the raw data of the fully automated ligand binding assay. The individual data point between duplicates is highly reproducible $(\mathrm{CV}=9.8 \%)$. The attached table summarizes the $\mathrm{K}_{\mathrm{i}}$ determined for haloperidol and L-741 626. The apparent $\mathrm{K}_{\mathrm{i}}$ values of haloperidol and L-741 626 are $5.0 \pm$ $0.6 \mathrm{nM}(n=60)$ and $96.3 \pm 15.3 \mathrm{nM}(n=24)$ respectively, very similar to the published values of these two compounds. The $\mathrm{CV}$ is between $12 \%$ and $15 \%$ for both compounds, again demonstrating the reproducibility of this hands-free assay. The reproducibility was superior to when the binding assay was performed manually (CV about $100 \%$, not shown).

A decrease of about $35 \%$ of the total binding was observed

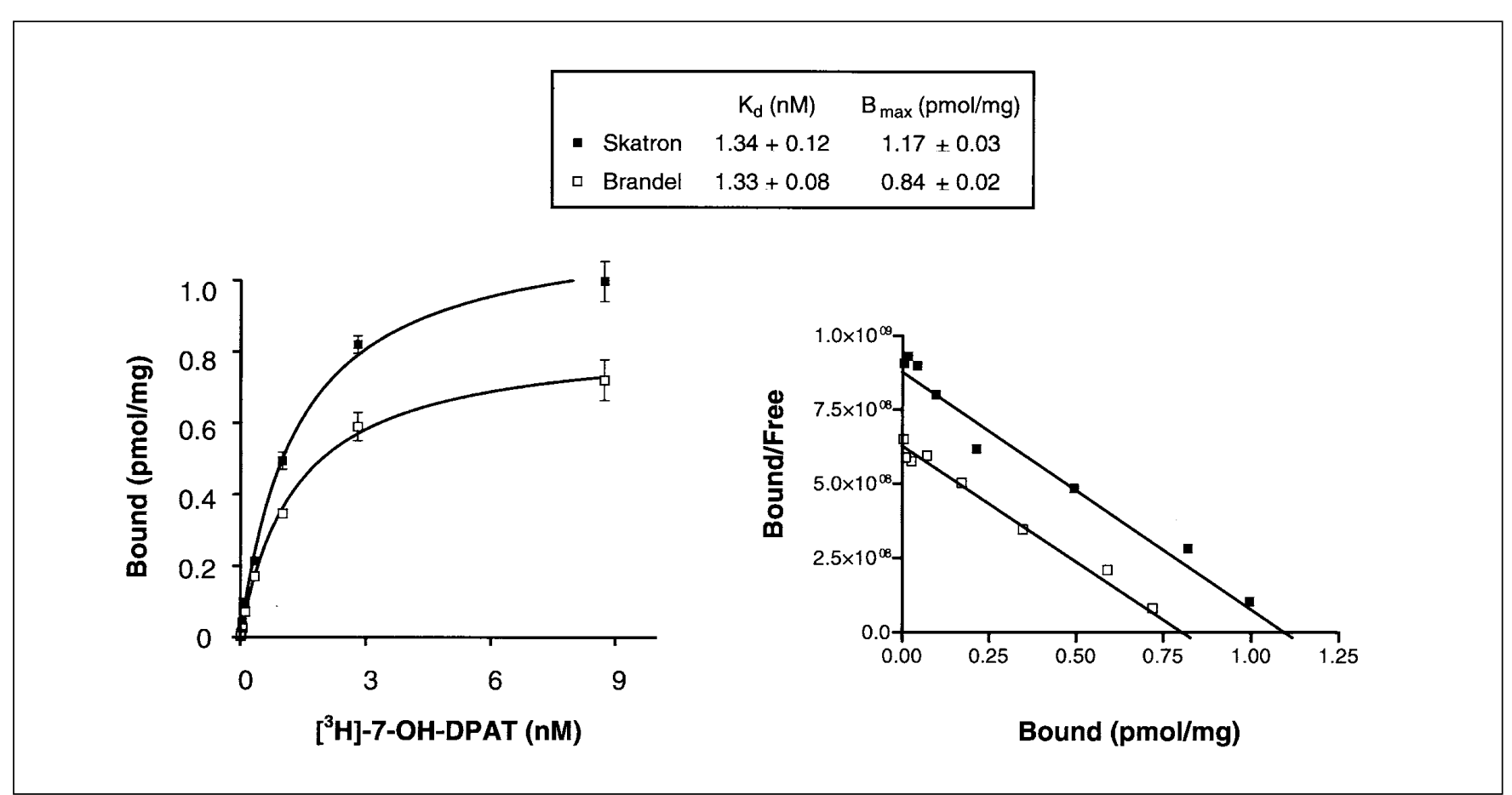

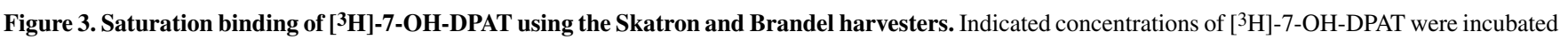
with the membranes from cells that overexpressed the human dopamine D3 receptors, as described in the Materials and Methods section. The samples were manually harvested either by the Skatron or Brandel harvester as shown. The amount of bound $\left[{ }^{3} \mathrm{H}\right]-7-\mathrm{OH}-\mathrm{DPAT}$ is shown on the left figure, while the right figure shows the Scatchard plot of the data. Results are typical of two independent experiments. The inset shows $\mathrm{K}_{\mathrm{i}}$ and $\mathrm{B}_{\max }$ values determined by the two harvesters. 
Table 1. Comparison of $K_{i}$ of $D 3$ Ligands from Automated Assay and Published Literature

\begin{tabular}{|lcc|}
\hline & \multicolumn{2}{c|}{$\mathbf{K}_{\mathbf{i}}(\mathbf{n M})$} \\
\cline { 2 - 3 } Compound & Automated & Published \\
\hline 7-OH-DPAT & $4.5 \pm 2.9$ & $2.2(8)$ \\
Quinelorane & $14.4 \pm 0.1$ & $6.1(8)$ \\
Quinpirole & $2.2 \pm 0.6$ & $43(8)$ \\
PD-128907 & $3.8 \pm 0.4$ & $1.8(9)$ \\
Raclopride & $10.7 \pm 2.9$ & $1.4(8)$ \\
Risperidone & $124.5 \pm 22.9$ & $11(8)$ \\
Clozapine & $10.6 \pm 2.8$ & $7.4(9)$ \\
Bromocriptine & & \\
The automated ligand binding assay was performed as de- \\
scribed in the Materials and Methods section, using the in- \\
dicated D3 agonists or antagonists. The $\mathrm{K}_{\mathrm{i}}$ values shown \\
are the $\bar{x} \pm$ SD of triplicate determinations from the same \\
experiment. The results shown are typical of two indepen- \\
dent experiments. The $\mathrm{K}_{\mathrm{i}}$ values determined are compared \\
with published values from the indicated references.
\end{tabular}

between the first and the twelfth plate. This is likely due to the denaturation of D3 upon storage in the assay buffer at $4{ }^{\circ} \mathrm{C}$. The decrease in receptor number did not affect the $\mathrm{K}_{\mathrm{i}}$ values, as internal controls were present in each plate.

Table 1 shows the $\mathrm{K}_{\mathrm{i}}$ of several D3 agonists and antagonists determined by the automated assay. The values are com-
Table 2. Comparison of the Time Required to Determine $\mathbf{K}_{\mathbf{i}}$

\begin{tabular}{|c|c|c|c|}
\hline \multirow[b]{2}{*}{ Operation } & \multirow{2}{*}{$\frac{\text { Manual }}{\text { Hands-On }}$} & \multicolumn{2}{|c|}{ Tecan } \\
\hline & & Hands-On & Machine \\
\hline Preparation of Reagents & 45 & 45 & \\
\hline $\begin{array}{l}\text { Dilution/Transfer/Incuation/ } \\
\text { Filtration }\end{array}$ & 135 & 0 & 230 \\
\hline Addition of Scintillation Fluid & 30 & 15 & \\
\hline Total (min) & 190 & 20 & 90 \\
\hline
\end{tabular}

pared to the published $\mathrm{K}_{\mathrm{i}}$ values, which were determined using antagonist $\left[{ }^{125} \mathrm{I}\right]$ iodosulpride. The $\mathrm{K}_{\mathrm{i}} \mathrm{s}(n=3)$ determined by the automated assay are in good agreement with the published values, and this further validates the hands-free assay.

\section{Time of Operation}

Minimal hands-on time was required as compared to manual operation. The total time of hands-on operation is about 1 h (Table 2). This compares favorably with the manual operation, which requires $3 \mathrm{~h}$ constant hands-on time to complete a similar task. The robotic operation thus saves more than $70 \%$ of the hands-on time. More importantly, the time of exposure to radioactivity is reduced by more than $95 \%$. Although the total time for the automated operation $(5 \mathrm{~h})$ is longer than manual operations $(3 \mathrm{~h})$, the fully automated operation has the

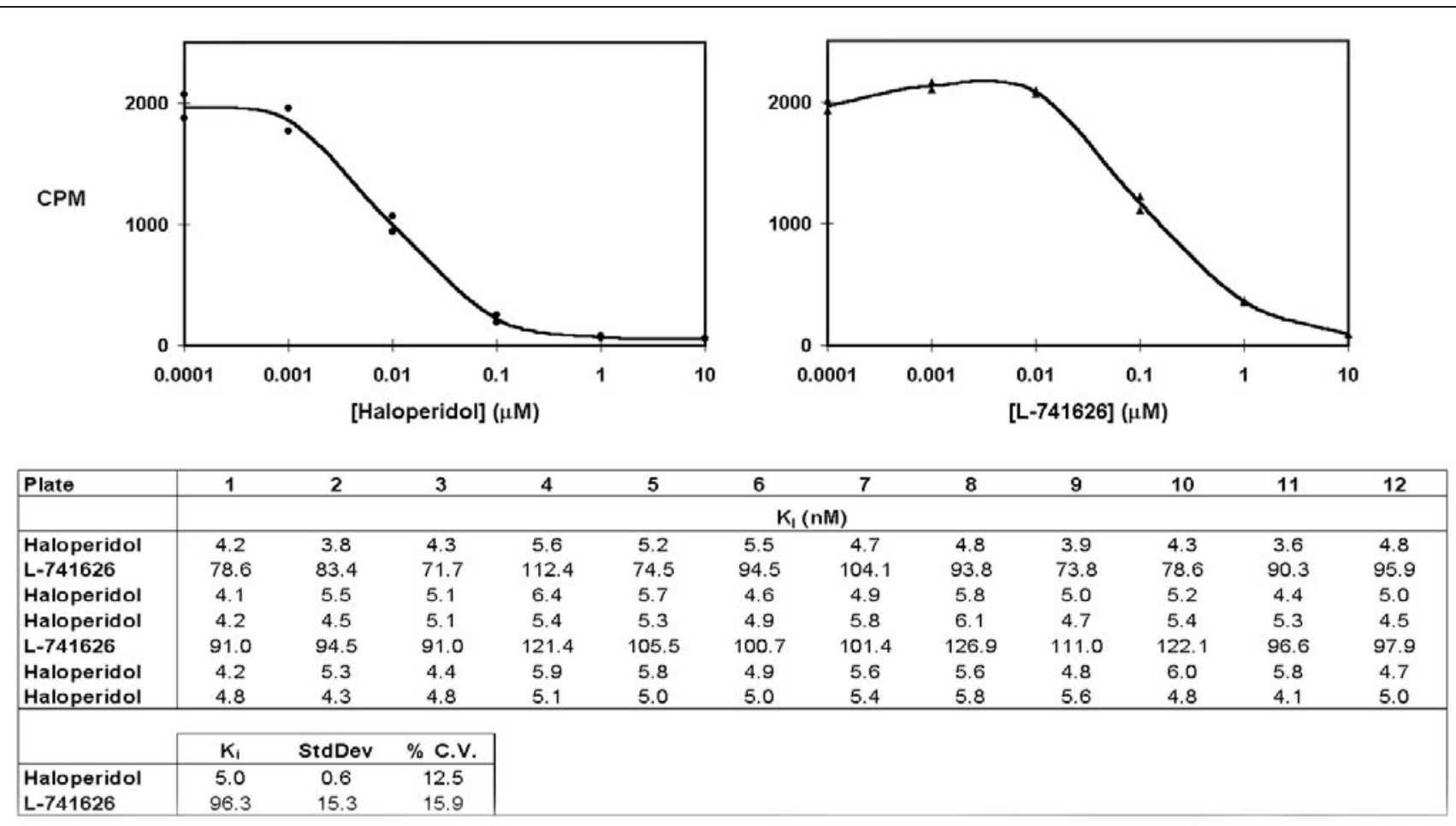

Figure 4. Competition binding of haloperidol and L-741 626 using the fully automated ligand binding assay. Haloperidol and L-741 626, at the indicated concentrations, were incubated with $\left[{ }^{3} \mathrm{H}\right]-7-\mathrm{OH}-\mathrm{DPAT}$ and membranes expressing D3 receptors, using the automated assay described in the Materials and Methods section. The two compounds were tested 24 times in 12 microplates. The figure shows representative binding isotherms of haloperidol and L-741 626 . The amount of bound $\left[{ }^{3} \mathrm{H}\right]-7-\mathrm{OH}-\mathrm{DPAT}(\mathrm{cpm})$ is shown in the binding isotherm. $\mathrm{K}_{\mathrm{i}}$ values generated are summarized in the table. The results shown are typical of at least three independent experiments. The binding isotherms of all the data can be found at http://www.BioTechniques.com/figures/Aug02/Wongfig4.html. 
distinct advantage of enabling the operator to walk away once the assay is initiated.

\section{DISCUSSION}

A fully automated radioligand binding procedure was described in this communication. The reproducibility, throughput, and hands-on time are superior to that of the manual operations. To our knowledge, this is the first publication of a fully automated system for rapid filtration binding assay. This system enables a fully automated assay setup in an ordinary laboratory setting and is suitable for the rapid determination of the structure-activity relationship of ligands of many membrane-bound receptors.

Disposable tips were used during compound dilution and transfer to avoid carryover. This is necessary because most the compounds used in neuroscience research are hydrophobic and have significant carryover, despite extensive washing of fixed tips by water and DMSO (not shown). The main obstacle to using disposable tips in an ordinary setting is the limitation of space in the robotic workstation. The use of the stackable pipet tips and the pipet tip holder overcame this difficulty. In the present layout format, as many as 36 cartridges of 96 disposable tips can be stored and delivered for the assay.

The reproducibility of the fully automated assay is superior to manual operations. The highly automated nature of the assay described here minimizes the variability of data as a result of the manual liquid handling. This enables an inexperienced operator, within a short training time (1-2 weeks), to produce high-quality data and with a throughput that is required for many drug discovery projects.

The throughput of the assay is only limited by the capacity of the equipment to store the assay and filter plates. In its current format, the equipment enables $\mathrm{K}_{\mathrm{i}}$ determination of 84 compounds per run. Three runs can be performed in a working day. The present format can be modified to single point percent inhibition experiments, where 24 microplates can be screened per run. If the assay is a homogeneous assay (such as the scintillation proximity assay, see below), then the throughput of the assay can be doubled, as a filter plate is not needed. The throughput can be further increased by the attachment of external plate stackers.

While newer technology such as the scintillation proximity assay eliminates the need to separate the free and the bound radioligand, the assay is not as universally used for membrane-bound receptors as the filtration binding assay. In our hands, radioligand binding assay of dopamine D3 receptors using $\left[{ }^{3} \mathrm{H}\right]-7-\mathrm{OH}-\mathrm{DPAT}$ and the scintillation proximity assay beads requires the use of 5- to 10-fold more radioactivity per well to yield sufficient signal over background. This is a result of the lower counting efficiency using the scintillation proximity beads. In addition, the $\mathrm{K}_{\mathrm{i}}$ determined for haloperidol was 5-10 times higher than that determined from the filtration binding assay (not shown). Thus, the scintillation proximity assay was not used for this receptor. The universal application of the rapid filtration assay for membrane-bound receptors would enable parallel screening of many different targets. Upon further development, as many as 96 different targets can potentially be screened in each run (one concentration per target, quadruplicate determinations), allowing fast and economical selectivity profiling of compounds.

The success in developing the automated assay can enable the development of many other automated assays. In addition to the selectivity profiling mentioned above, the scheduling operation of the assay allows identical incubation times between plates. This enables the automation of functional assays where termination of incubation by rapid filtration is required at fixed time interval (e.g., serotonin uptake assays).

\section{ACKNOWLEDGMENTS}

We thank John Drohen, Jennifer Parturzo, and Jonathan Alden from Tecan for their help in setting up the robotics.

\section{REFERENCES}

1.Bowery, B.J., Z. Razzaque, F. Emms, S. Patel, S. Freedman, L. Bristow, J. Kulagowski, and G.R. Seabrook. 1996. Antagonism of the effects of (+)-PD 128907 on midbrain dopamine neurones in rat brain slices by a selective D2 receptor antagonist L-741,626. Br. J. Pharmacol. 119:1491-1497.

2.Cusack, B. and E. Richelson. 1993. A method for radioligand binding assays using a robotic workstation. J. Recept. Res. 13:123-134.

3.Freeman, S.B., S. Patel, R. Marwood, F. Emms, G.R. Seabrook, M.R. Knowles, and G. McAllister. 1994. Expression and pharmacological characterization of the human D3 dopamine receptor. J. Pharmacol. Exp. Ther. 286:417-426.

4.Levant, B. 1997. The D3 dopamine receptor: neurobiology and potential clinical relevance. Pharmacol. Rev. 49:231-252.

5.Liebl, B., T. Anhaupl, E. Haen, B. Gunster, and M. Georgieff. 1993. A partially automated radioligand binding assay for use in clinical and pharmaceutical research. J. Recept. Res. 13:369-378.

6.Mackenzie, R.G., D. VanLeeuwen, T.A. Pugsley, Y.H. Shih, S. Demattos, L. Tang, R.D. Todd, and K.L. O'Malley. 1994. Characterization of the human dopamine D3 receptor expressed in transfected cell lines. Eur. J. Pharmacol. 266:79-85.

7.Marquardt, D.W. 1963. An algorithm for least squares estimation of nonlinear parameters. J. Soc. Ind. Appl. Math. 11:431-441.

8.Millan, M.J., J.L. Peglion, J. Vian, J.M. Rivet, M. Brocco, A. Gobert, A. Newman-Tancredi, C. Dacquet, et al. 1995. Functional correlates of dopamine D3 receptor activation in the rat in vivo and their modulation by the selective antagonist, (+)-S 14297: 1. Activation of postsynaptic D3 receptors mediates hypothermia, whereas blockade of D2 receptors elicits prolactin secretion and catalepsy. J. Pharmacol. Exp. Ther. 275:885-898.

9.Sautel, F., N. Griffon, D. Levesque, C. Pilon, J.C. Schwartz, and P. Sokoloff. 1995. A functional test identifies dopamine agonists selective for D3 versus D2 receptors. Neuroreport 6:329-332.

10.Sokoloff, P., B. Giros, M.P. Martres, M.L. Bouthenet, and J.-C. Schwartz. 1990. Molecular cloning and characterization of a novel dopamine receptor (D3) as a target for neuroleptics. Nature 347:146-151

11.Sokoloff, P., B. Giros, M.P. Martres, M.L. Bouthenet, and J.-C. Schwartz. 1992. Pharmacology of humna D3 receptor expressed in a mammalian cell line: comparison with D2 receptor. Eur. J. Pharmacol. 225:331-337.

Address correspondence to Dr. Stephen K-F. Wong, Department of Neuroscience, Pfizer Global Research and Development, Pfizer, Easter Point Road, Groton, CT 06340, USA. e-mail: stephen_wong@groton.pfizer.com 